\title{
Wilt-Causing Fungal Pathogens of Banana
}

\author{
Puja Kumari, Ngangbam Sushma*, Lourembam Saaya Devi, Samreen Taj, \\ Neha Jit, Jayarama Reddy
}

Department of Botany, St. Joseph's College (Autonomous), 36, Lalbagh Road, Bengaluru 560027

Received: 12-01-2022 / Revised Accepted: 29-01-2022 / Published: 01-02-2022

\begin{abstract}
This study sought to utilize indigenous soil micro-organisms to suppress wilt-causing fungal pathogens of the banana. Fungal pathogens were isolated from wilt-affected rhizospheric soil, and potential antagonistic bacterial strains were isolated from healthy rhizospheric soil in the same area from which fungal pathogens were isolated. The antifungal activity of isolated micro-organisms against fungal pathogens was studied both in vitro and in vivo against fungal pathogens. It was found that Fusarium oxysporum and Alternaria sp. were pathogenic, while Penicillium sp. Bacillus velezensis and Bacillus subtilis were antagonistic. Moreover, it was seen that B. velezensis, B. subtilis and Penicillium sp. Inhibited the growth of the two fungal pathogens in both in vitro and in vivo experiments. An antagonistic consortium isolated in this study has demonstrated remarkable potential for controlling fungal diseases caused by Fusarium sp. and Alternaria sp. Therefore, the use of indigenous microflora to improve disease suppression of banana plants against soil-borne pathogens is a preferable approach.
\end{abstract}

Keywords: wilt-causing; fungal pathogens; banana

\section{INTRODUCTION}

Fusarium wilt is one of the most common diseases in all soil types around the world which results in a heavy economic reduction in most of the global banana production. These diseases are known to be a major biological limiting factor for the development of the present banana industry. Historically, the infection spread to the xylem of banana plantations and eventually destroyed most of the banana plant Amani and Avagyan (2014) reported that F. oxysporum was isolated from banana root, pseudo stem and fruit (wallery and robusta), which caused necrosis, wilt and rot also stated that F. oxysporum is a post-harvest fruit rot pathogen. Apart from Fusarium wilt the occurrence of another species of the pathogenic fungi Alternaria sp. that causes leaf disease that has been reported in infected banana plantations. The cooccurrence of both pathogens in bananas and their control has yet to be reported. To date, various approaches have been applied to cope with wilt control, including a chemical method based on specific fungicides, physical method biological

Address for Correspondence: Ngangbam Sushma, Department of Botany, St. Joseph's College (Autonomous), 36, Lalbagh Road, Bengaluru 560027; E-mail: ngsushma1999@gmail.com

How to Cite this Article: Puja Kumari, Ngangbam Sushma, Lourembam Saaya Devi, Samreen Taj, Neha Jit, Jayarama Reddy. Wilt-Causing Fungal Pathogens of Banana. World J Pharm Sci 2022; 10(02): 208212; https://doi.org/10.54037/WJPS.2022.100206

Copyright:2022@ The Author(s). This is an open access article distributed under the terms of the Creative Commons AttributionNonCommercial-ShareAlike 4.0 International License (CC BY-NC-SA), which allows re-users to distribute, remix, adapt, and build upon the material in any medium or format for noncommercial purposes only, and only so long as attribution is given to the creator. If you remix, adapt, or build upon the material, you must license the modified material under identical terms. 
control (application of bacteria, fungi such as Trichoderma, Actinobacteria and Bacillus, etc.) and breeding/selection of disease-resistant banana Among them, physical and biological methods become attractive as they have no environmental impacts varieties. The use of biological control agents to protect and promote plant growth through colonization and multiplication in both rhizosphere and plant system could be a promising approach to manage wilt of bananas. However, this approach still has many difficulties to overcome Indigenous micro-organisms are a group of endogenous microbial consortia that inhabit the soil, which can be used for environmental and agricultural purposes. Indigenous micro-organisms can express microbial antagonism and inhibit the growth and development of fungal pathogens in various ways, including the production of specific antifungal compounds (antibiosis), competition for growth, (myco)-parasitism and predation. Our work focuses on the biocontrol of banana wilt diseases caused by Fusarium sp. and Alternaria sp. using strains of indigenous micro-organisms isolated from diseasesuppressive soil. Phytopathogenic fungi and their receptive antagonistic microbes were isolated from banana cultivation lands. The antagonistic effects of these isolates on phytopathogens were evaluated through in vitro antagonistic assays. In vivo pot trials were also conducted to evaluate the efficacy of a consortium of bio-control agents against the wilt diseases.

\section{MATERIALS AND METHODS}

Soil samples were collected from banana orchards at Guangxi Academy of Agricultural Science, Nanning, China. naturally wilt-affected banana rhizospheric soil and rhizospheric soil of healthy banana plants. The incidence of disease in sampled plantations was about $60 \%$ of total plants.

Samples were collected via random sampling method from 150 to $200 \mathrm{~mm}$ depth rhizospheric soil. Soil samples were packed in sterile bags and kept on ice during transportation and stored at $4{ }^{\circ} \mathrm{C}$ for further studies. Isolation and identification of micro-organisms under study. Isolation and identification of pathogenic fungi, Isolation and identification of Bacillus strains

\section{Methodology}

Isolation and identification of pathogenic fungi

Fungal isolation was performed using potatoes dextrose agar (PDA) media supplemented with Rose Bengal (0 02 g 1-1) and chloramphenicol (50mg 1-1) (Gil et al. 2009) to inhibit the bacterial growth. In detail, $1 \mathrm{~g}$ of rhizospheric soil around the wilt-affected banana plant was collected and transferred to a $250 \mathrm{ml}$ conical flask containing 100 $\mathrm{ml}$ of sterile distilled water (Pitt and Hocking 1988;
Leslie and Summerell 2006; Woudenberg et al. 2013). After shaking the soil solution for $10 \mathrm{~min}$ at $120 \mathrm{rev} \min 1,1 \mathrm{ml}$ of the supernatant was taken and diluted serially (107 times), after which $1 \mathrm{ml}$ of each dilution was poured into the prepared PDA medium.

\section{Isolation and Identification of Bacillus strains}

Bacterial strains were isolated from rhizospheric soil around healthy banana plants using LuriaBertani (LB) medium, supplemented with cyclohexamide (50 mg 1-1) to inhibit fungal growth, by serial dilution method like the method for serial dilution of fungal strains (refer to Isolation and identification of pathogenic fungi section) (Weisburg et al.1991). After $48 \mathrm{~h}$ incubation, bacterial isolates were enumerated and differentiated by colonial morphology (i.e., size, shape and colour; Thangavelu 2015). Individual colonies were purified by streaking on LB agar medium. For further analysis, bacterial isolates' glycerol stock cultures were maintained at $-80^{\circ} \mathrm{C}$.

\section{Screening of potential antifungal properties of isolated antagonist strains}

In order to screen the potential antifungal activity of isolated bacterial strains for their potential use as biocontrol agents (Zivkovi'c et al. (2010), three methods were followed, which are:1) Dual-plate assay (competitiveness), Scanning electron microscopic studies, Effect of metabolite extracts on fungal growth inhibition(antibiosis), Fungal growth inhibition study.

\section{In vivo experimental conditions}

All pots were watered to saturation and placed in a greenhouse at Beijing University of Chemical Technology $\left(39^{\circ} 5802^{\prime \prime} \mathrm{N}, 116^{\circ} 2502^{\prime \prime} \mathrm{E}\right)$, receiving $12 \mathrm{~h}$ sunlight each day with fluctuating day temperatures of $30-35^{\circ} \mathrm{C}$ and $20-24^{\circ} \mathrm{C}$ at night. The plantlets were watered once a day from the second day onwards, and no fertilizer was applied to the soil. After the 9th week of infection and treatment, wilt severity assessments were recorded. All plants' disease symptoms were evaluated according to a five-class variation from 0 to 4. 0-no yellowing of the leaves, the plant looks healthy; 1light yellowing of the lower leaves; 2-yellowing of the lower leaves; 3-yellowing of most or all the leaves and 4-dead plant.

\section{RESULTS}

Total fungal count in the wilted rhizospheric soil was found to be $24 \times 104 \mathrm{CFU}$ per $\mathrm{g}$. Of numerous colonies, three colonies, i.e., white cottony colony, white colony with green margin and thick colony which has dark green colour, were found to be dominating in the soil sample with distinct morphology. These colonies were selected and 
subculture to test their pathogenicity in vivo. in vivo investigation of the pathogenicity of the identified fungal strains on banana plantlet sand fruits was performed (as illustrated in (Fig. 1a-c). In vivo experiments with single isolates of $B$. subtilis, B. velezensis or Penicillium sp. were shown to suppress wilt development without any statistical significance. It was observed that in the in vivo experiments, the combination of isolates $\mathrm{B}$. subtilis, B. velezensis and Penicillium sp. reduced the disease severity to the greatest degree and controlled both phytopathogens up to $60-63 \%$. The combined application of $\mathrm{B}$. subtilis $+\mathrm{B}$. velezensis
+ Penicillium sp. gave a significant reduction of disease severity among the tested combinations. This combination significantly reduced the disease severity and increased control. Control plants that were infected with both F. oxysporum and Alternaria sp. showed the characteristic wilt symptoms, and the disease severity index reached as high as $84-92 \%$. It also showed that there was no significant difference between the tested isolates when used individually. In contrast, the combination of all isolates, disease severity was significantly lower than the untreated control plants.
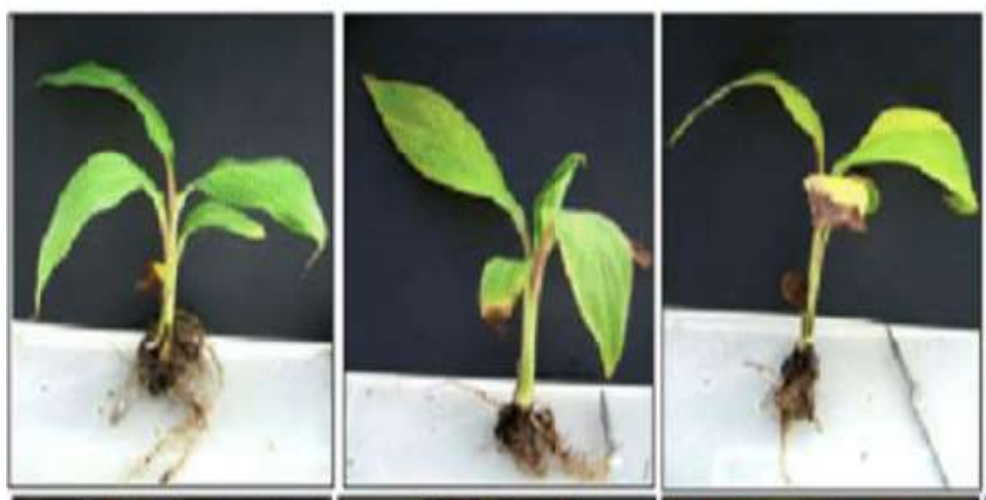

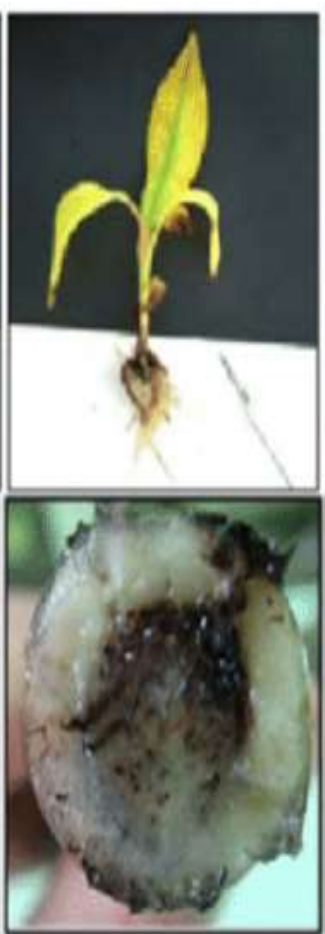

4

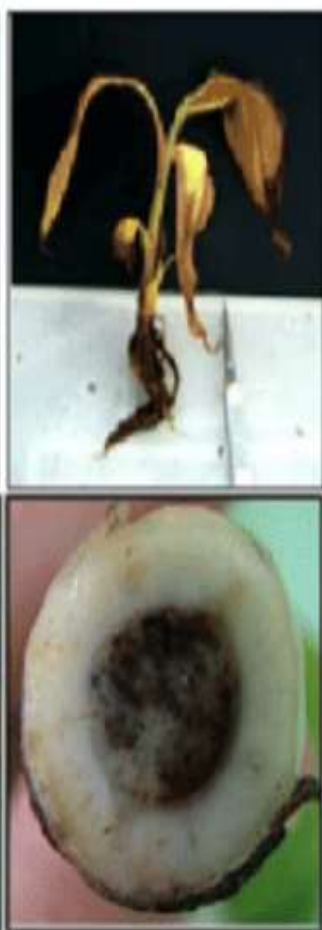

5

Figure 1: Scale for evaluation of Fusarium wilt of banana in greenhouse conditions based on external (upper panel) and internal symptoms (lower panel). Classes for external symptoms are: 1: No symptoms; 2: Initial yellowing mainly in the lower leaves; 3: Yellowing of all the lower leaves with some discoloration of younger leaves; 4: All leaves with intense yellowing; 5: Plant dead. Class for internal symptoms are: 1: No symptoms; 2: Initial rhizome discoloration; 3: Slight rhizome discoloration along the whole vascular system; 4: Rhizome with most of the internal tissues showing necrosis; 5: Rhizome totally necrotic. Source: http://www.scielo.org.mx/scielo.php?script=sci_arttext\&pid=S0187-5779202000030043

\section{DISCUSSION}

To establish an effective control and management system, identifying the disease-causing agents is the preliminary necessity (Miller et al. 2009). In this study, two fungal isolates (F. oxysporum and Alternaria sp.) have been introduced for their pathogenicity with banana plantlets and fruits. Their macro- and micro-morphological structure were also consistent with the previous studies (Leslie and Summerell 2006; Woudenberg et al. 2013).
The observed disease symptoms were consistent with the description of symptoms shown by Jamil et al. (2019). The observed smaller yellowing surfaces as formed by F.oxysporum compared to Alternaria sp. could be explained as F.oxysporum predominantly penetrates roots, but not photosynthetic tissues (Stover 1962; Avagyan 2014). In addition, Alternaria sp. directly penetrates the host, through wounds or through stomata (Laemmlen 2002). Once the disease has been identified, bacterial antagonists were screened 
against Fusarium sp. and Alternaria sp. For their biocontrol activity (Zivkovi'c et al. 2010). The present work made an attempt to isolate antagonist bacterial strains that could be used as biocontrol agents. The fungal isolate identified here as Penicillium sp. further showed the macro- and microscopic structure. Another interesting observation was that the metabolite extract of the antagonist bacterial strains could alter the growth of mycelium of the pathogenic fungi from $38 \%$ to $56 \%$ after 7 days of incubation at $281^{\circ} \mathrm{C}$. Growth of pathogens was inhibited in the presence of these antagonistic metabolites extract. The reduction in growth via metabolite extract of antagonist bacteria may be noted with the corresponding potential suppression of the fungal pathogen activity in the soil. It can also be assumed that the antagonists could reduce the invasion and subsequent development of pathogenic fungi, suggesting a high potential for biocontrol ability. Chitinase and $\beta-1,3-$ glucanase are the key enzymes associated with the decomposition of the fungal cell wall, involved in myco-parasitism. These enzymatic activities have thus been previously used to evaluate the antifungal potential of various biological antifungal agents (Mendoza and Sikora 2009; Tan et al. 2015; Kohl et al.2019). This work has also focused on the activities of chitinase and $\beta$-1,3-glucanase by growing the antagonist microorganisms under noninduced conditions, i.e. LB medium, without any supplementation. The final disease control effect was between 24 and $63 \%$ in our in vivo study. These findings showed the ability of the isolated strains to survive in the host rhizospheric soil and the isolates' adaptability to the soil environment. Thus, the antagonist isolates depict the potential to control banana disease under field conditions. However, their co-existence as a consortium must be confirmed by an in vitro compatibility test. Further research on the biocontrol activity of these strains must be attempted with an enhancement of antifungal enzymes production from biocontrol agents and increasing resistance of biocontrol agents against environment constraints. In this study, two bacterial isolates and one fungal isolate showed a significant reduction in disease incidence against isolated phytopathogens. In particular, the mixture of all three isolates showed significance in disease suppression for both F. oxysporum and Alternaria sp. The use of indigenous microflora for the improvement of disease suppression of banana plants against soil-borne pathogens is a preferable approach, and further research is needed. These results support further investigation of the modes of action of the biocontrol agents at the molecular level, for example, via mutation studies focus on enhancement of antifungal enzymes production from biocontrol agents and increasing resistance of biocontrol agents against environment constraints.

\section{References}

1. Adebesin, A.A., Odebode, C.A. and Ayodele, A.M. Control of postharvest rots of banana fruits by conidia and culture filtrates of Trichoderma asperellum, J Plant Prot Res (2009) 49, 302-308.

2. Bull, A.T. and Chesters, C. The biochemistry of laminarin and the nature of laminarinase. Adv Enzymol Relat Areas Mol Biol 28, (1966) 325-364.

3. Claude Alabouvette, C.O., Migheli, Q. and Christian, S. Microbiological control of soil-borne phytopathogenic fungi with special emphasis on wilt-inducing Fusarium oxysporum. New Phytol 184, (2009) 529-544.

4. Elkhayat, E.S. and Goda, A.M. Antifungal and cytotoxic constituents from the endophytic fungus Penicillium sp. Bull Fac Pharm Cairo Univ 55, (2017) 8 5-89.

5. Gang, G., Bizun, W., Weihong, M., Xiaofen, L., Xiaolin, Y., Chaohua, Z., Jianhong, M. and Huicai, Z. Biocontrol of Fusarium wilt of banana: key influence factors and strategies. Afr J Microbiol Res 7, (2013) 4835-4843.

6. Henis, Y. and Chet, I. Microbiological control of plant pathogens. Adv Appl Microbiol 19, (1975) 8 5111.

7. Nel, B., Steinberg, C., Labuschagne, N. and Viljoen, A. Evaluation of fungicides and sterilants for potential application in the management of Fusarium wilt of banana. Crop Prot 26, (2007) 697-705.

8. Perez-Vicente, L. Fusarium wilt (Panama disease) of bananas: an updating review of the current knowledge on the disease and its causal agent. Agris 8, (2004) 2 7-38.

9. Reese, E.T. and Mandels, M. $\beta$-D-1, 3 glucanases in fungi. Can J Microbiol 5, (1959) 173-185.

10. Shen, C.-R., Chen, Y.-S., Yang, C.-J., Chen, J.-K. and Liu, C.-L. Colloid chitin azure is a dispersible, low-costsubstrate for chitinase measurements in a sensitive, fast reproducible assay. J Biomol Screen 15, (2010) 213-217.

11. Smith, P.K., Krohn, R.I., Hermanson, G.T., Mallia, A.K., Gartner, F.H., Provenzano, M.D., Fujimoto, E.K., Goeke, N.M., Olson, B.J. and Klenk, D.C. Measurement of protein using bicinchoninic acid. Anal Biochem 150, (1985) 76-85. 
12. Tan, D., Fu, L., Han, B., Sun, X., Zheng, P. and Zhang, J. Identification of an endophytic antifungal bacterial strain isolated from the rubber tree and its application in the biological control of banana Fusarium wilt. PloS One,10, e0131974(2015).

13. Whipps, J.M. Developments in the biological control of soil-borne plant pathogens. Adv Bot Res 26, (1997) 1-134.

14. Yip, M.-K., Lee, S.-W., Su, K.-C., Lin, Y.-H., Chen, T.-Y. and Feng, T.-Y. An easy and efficient protocol in the production of pflp transgenic banana against Fusarium wilt. Plant Biotechnol Rep 5, (2011) 245-254.

15. Zivkovi'c, S., Stojanovi'c, S., Ivanovi'c, Z., Gavrilovi'c, V., Popovi'c, T. and Bala`z, J. Screening of antagonistic activity of microorganisms against Colletotrichum acutatum and Colletotrichum gloeosporioides. Arc Biol Sci 62, (2010) 611. 